\title{
A Civilian Reporting Service to Guide Converging Resources for Search and Rescue in Disaster Response
}

\author{
Albert Y. Chen ${ }^{1}$, SangUk Han ${ }^{2}$, SangHyun Lee ${ }^{3}$, and Feniosky Peña-Mora ${ }^{4}$
}

\begin{abstract}
During disaster response, prioritization of limited resources is one of the most important but challenging tasks. At the same time, it is imperative to timely provide to the rescuers with the adequate heavy equipment to facilitate lifesaving operations. However, supply of high demand equipment is usually insufficient during the initial phase of disaster response, challenging lifesaving operations. At the same time, resources outside of the disaster affected zone converge into the area to assist the response efforts, which is the effect of convergence that often made resource coordination challenging in large scale disasters. Meanwhile, the initial condition of the disaster is usually best known by civilians already at the area before and during impact of the disaster. The knowledge of the civilians is not always received and considered by the responding organizations. With the help of these civilians, critical information such as victim location, infrastructure damage, and risk condition could be better known before any response actions are taken. To efficiently collect information and utilize the converging resources, this paper proposes a geospatial information repository for initial condition reporting and update to guide search and rescue operations and deployment of equipment with safety considerations for the rescuers in large scale disaster response scenarios.
\end{abstract}

Keywords: Construction Equipment, Disaster Response, Resource Convergence, Urban Search and Rescue (US\&R), Safety

\section{INTRODUCTION}

During disaster response, it is imperative to timely provide the rescuers with the adequate equipment to facilitate lifesaving operations [1, 2]. However, facilities management of geographically distributed resources has been recognized as one of the most important but challenging tasks in disaster response [3, 4]. Challenges include demand identification for search and rescue, resource assignment, location tracking and delivery [4, 5]. In addition, the convergence of resources makes coordination of response resources difficult [6]. These challenges must be addressed to have disaster response efforts become more effective.

\section{BACKGROUND}

In response to disasters, the initial efforts including information gathering, victims search and rescue are sometimes carried out by civilians within the area at the time when the disaster occur $[7,8,9]$. Organizations and individuals from different industries and background work together in response to the crisis collectively [8, $10,11,12]$. Individuals collect relief supplies, provide shelter, and engage in a variety of services [7, 13]. At the same time, the establishment of the official command and control system by the Emergency
Management Agencies (EMAs) from the local, state and federal takes time, to coordinate and respond to the disaster [7, 8, 9]. Meanwhile, volunteers and response organizations outside of the disaster affected zone converges into the disaster affected area to assist disaster response. This is the effect of convergence that often made the already complex problem of resource coordination challenging $[3,6,7,10]$. For example, onsite congestion of volunteers, material, and equipment hinders efficient resource coordination [7, 10]. However, provided with the converging resources, the response to the incident could become more effective $[7,9,14,15$, 16]. In rapidly changing environments, the convergence could bring certain capabilities and flexibilities that do not exist or is not sufficient in the command and control system [10]. How to properly manage the converging resources is the important task.

One of the greatest challenges of utilizing the converging resources is their ability to be deployed immediately to the incidents without the appropriate and required skills, training and the familiarity to the command and control structure and EMAs [10]. Nevertheless, there are still great potential to utilize the converging resources. For example, Red Cross [11] is one of the specialized organizations, along with other

\footnotetext{
${ }^{1}$ Assistant Professor, Department of Civil Engineering, National Taiwan University, No. 1, Sec. 4, Roosevelt Road, Taipei, 10617, Taiwan; email: AlbertChen@ntu.edu.tw

${ }^{2}$ Ph.D. Candidate, Department of Civil and Environmental Engineering, University of Illinois at Urbana-Champaign, 205 N. Mathews Ave., Urbana, IL 61801; email: han12@illinois.edu

${ }^{3}$ Assistant Professor, Department of Civil and Environmental Engineering, University of Michigan, 2350 Hayward, 2356 GG Brown, Ann Arbor, Michigan 48109-2125; email: shdpm@umich.edu

${ }^{4}$ Dean of The Fu Foundation School of Engineering and Applied Science and Morris A. and Alma Schapiro Professor, Columbia University, 510 S.W. Mudd Bldg, 500 W. 120th St., New York, NY 10027 email: feniosky@ columbia.edu
} 
specialized entities, that contributed to the response operations in the 9-11 terrorist attaches [10]. In addition, Kendra and Wachtendorf [10] pointed out that to have an efficient and effective disaster response, it is vital to develop, maintain and take action based on a "Shared Vision" of emergency goals, critical tasks and their need of critical resources. It is difficult to have the volunteers obtain such Shared Vision without any prior training and communication with the EMAs.

\section{OBJECTIVE}

When disasters occur, information required to guide the initial urban search and rescue operations is not always available. For example, before the Haiti Earthquake, there is very little information regarding the road network and spatial entities in their digital maps. After the earthquake, this lack of information hindered the response operations. However, volunteers in Portau-Prince filled in cartographic blanks in maps with more detailed information that are accessible to the public online [17]. It is also important to understand that the initial information collected about the disaster is often inaccurate [18]. For this reason, assessment of resource needs has to be an ongoing procedure that continues throughout the duration of the incident to update information for all entities involved within the disaster response operations to provide stakeholders and decision makers an accurate view of the condition and needs [9]. In the case of Haiti, the volunteers used text messages, GPS, and hand drawings to dispatch thousands of updates for road names, building collapse, and victim locations [17, 19]. The officials used the information to guide their emergency workers, including the Marine Corps and Red Cross [19]. Although there are drawbacks in this approach of information collection and update, the benefits outweighed in the case of the Haiti earthquake [17, 19].

Inspired by the aforementioned fact, the objective of this paper is to establish a public web service for civilians to report, update, and share information that could potentially be used by officials in the command and control system and volunteering personal, equipment and materials.

\section{APPROACH}

An innovative approach that facilitates immediate equipment distribution in response to disasters is proposed by Chen and Peña-Mora [20]. An Equipment Control Structure, which is inspired by the behavior of honeybees' foraging [21], enables a decentralized and collective decision making process for equipment prioritization and response. With the Equipment Control Structure applied to facilities management such as construction equipment distribution, disaster response operations have the potential to become more efficient in the case when the command and control system is overloaded. Each volunteering Equipment Unit will make its own decision on where it will carry out the disaster relief effort. How each Equipment Unit makes decisions based on the information it perceives is inspired by Honeybees' foraging behavior [20].

Based on the decentralized approach Chen and PeñaMora proposed for the converging resources [20], the proposed web service could provide the converging resources a source of information as to guide how victim locations are prioritized and where the resources should respond to.

Figure I shows the outline process a civilian would follow for using the Civilian Report server.

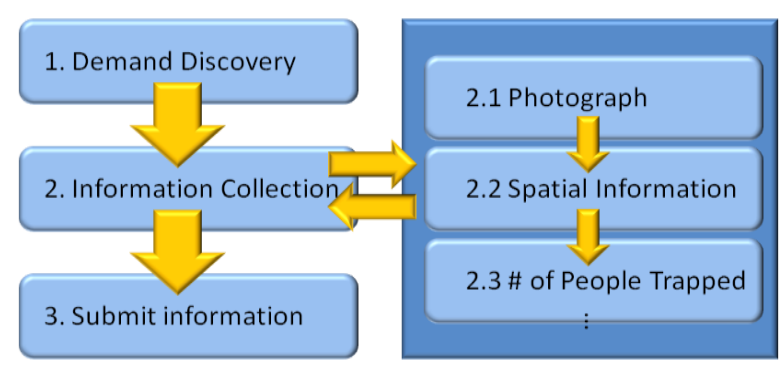

FIGURE I

OUTLINE PROCESS

When a person in the disaster affected area discovers a location where there are victims that need help, e.g. victims are trapped under collapsed structural elements, the person could report such situation to the Civilian Report service through a handheld device such as a smart phone, a laptop or a touchpad device, with network capability. The information uploaded by the civilians could be seen through a digital map. As a result, the Civilian Report service could play the role of an information hub for unassigned disaster response resources. By visiting the Civilian Report webpage, individual Equipment Units could learn more about the condition of the disaster and decide what location it will respond to. This way the productivity of the unassigned resources could greatly increase, avoiding unnecessary idle due to the overload of the official command and control system.

To achieve this goal, there are certain assumptions. First, we assume that there will be access to computer network such as a wireless $3 \mathrm{G} / 4 \mathrm{G}$ network. In cases if infrastructure based networks are not presented, an ad hoc network approach could be taken [22]. Secondly, at the current stage of the development, we assume there will not be malicious injections of information into the database. The primary goal of the Civilian Report webpage is to guide search and rescue operations at the initial stage of disaster response. However, under the condition when the official command and control system is saturated, the Civilian Report service could continue to function to communicate information to the responding resources. In other words, when the When a person in the disaster affected area discovers a location where there are victims that need help, e.g. victims are 
trapped under collapsed structural elements, the person could report such situation to the Civilian Report service through a handheld device such as a smart phone, a laptop or a touchpad device, with network capability. The information uploaded by the civilians could be seen through a digital map. As a result, the Civilian Report service could play the role of an information hub for unassigned disaster response resources. By visiting the Civilian Report webpage, individual Equipment Units could learn more about the condition of the disaster and decide what location it will respond to. This way the productivity of the unassigned resources could greatly increase, avoiding unnecessary idle due to the overload of the official command and control system.

To achieve this goal, there are certain assumptions. First, we assume that there will be access to computer network such as a wireless $3 \mathrm{G} / 4 \mathrm{G}$ network. In cases if infrastructure based networks are not presented, an ad hoc network approach could be taken [22]. Secondly, at the current stage of the development, we assume there will not be malicious injections of information into the database. The primary goal of the Civilian Report webpage is to guide search and rescue operations at the initial stage of disaster response. However, under the condition when the official command and control system is saturated, the Civilian Report service could continue to function to communicate information to the responding resources. In other words, when the command and control system is overloaded by the massive tasks to be carried out, such as urban search and rescue, resource location, assignment and coordination, unassigned resources could use the Civilian Report service to find locations of resource demand to respond to.

The system architecture of the Civilian Report service is shown in Figure II, which includes a database as the information repository, a web hosting service, and the webpage itself and external geo-spatial representations. The implementation of the web service is as follows: MySQL is chosen as the database to store the discovered information. The database table (Figure III) that holds such information includes attributes such as the entry key/id, the timestamp of when the piece of information is received, the latitude and longitude coordinates of the location, a photograph of the situation, potential number of victims, the condition of the victims, textual comments of the image, name and phone number of the person who reported, and safety condition of the location. The web interface is written in a mixture of PHP and HTML. PHP is selected for its easy access to databases and the ability to program logic in HTML web pages. In addition, the Google Maps JavaScript V3 API [23] is used to display spatial information with the PHP Google Map API [24]. Figure IV shows the upload interface that includes all the information needed by the Civilian Report database. After civilians click the Upload Button, the photo and comments submitted are automatically inserted to the MySQL database and the Civilian Report service retrieves the photo and comments from the MySQL database and shows the information on the map through the Google Maps API. The result is shown in Figure V.

People who are interested in helping the disaster relieve efforts could visit the web service and see where help is needed. For example, if a truck mounted crane and its crew is volunteering to help while the official command and control system is overloaded, the crew could visit this webpage. Through the information the Civilian Report service provides, the crew could decide where they could be most helpful.
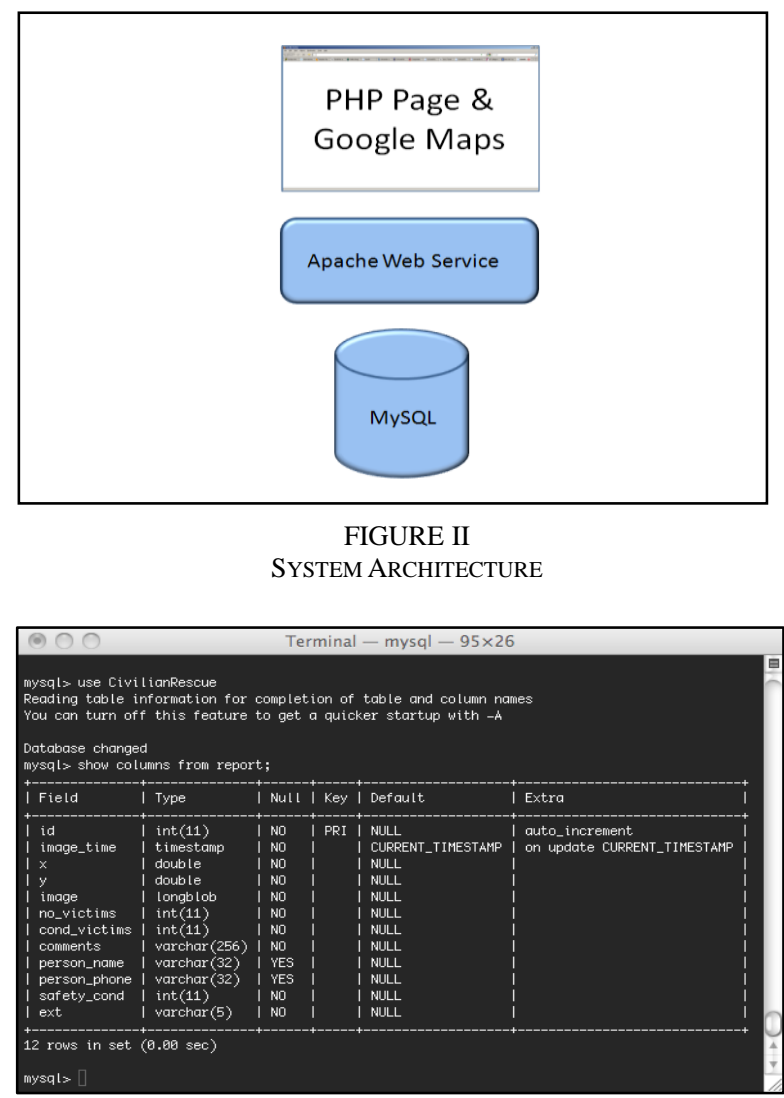

FIGURE III

DATABASE OF CIVILIAN REPORT

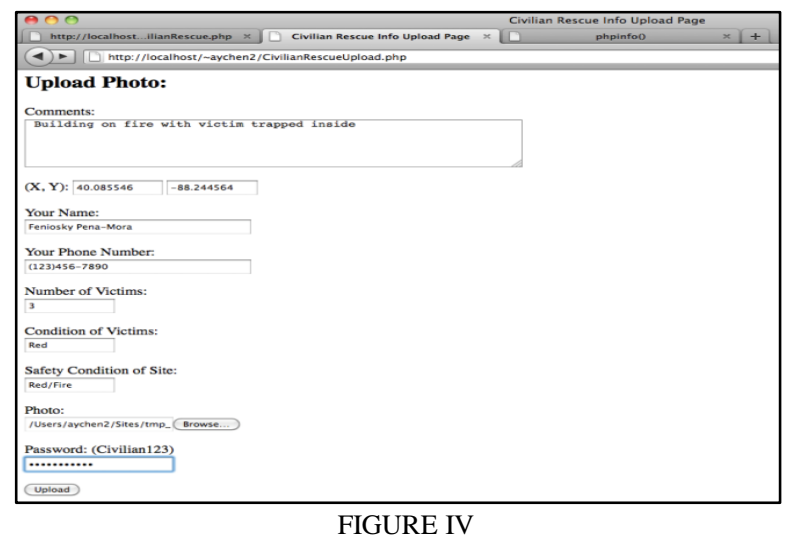

DATABASE OF CIVILIAN REPORT 


\section{SAFETY IN SEARCH AND RESCUE OPERATION}

In the previous sections, the Civilian Report web service is discussed and it provides a platform designed for reporting, updating and communicating damage and resource needs in disaster response as well as for facilitating volunteers to help rescue operations. When the official command and control system is overloaded, in particular, this approach can be more useful to rescue survivors as providing a way that volunteers can easily assist and participate in the lifesaving operations. Once arriving at the site, however, search and rescue personnel and volunteers is exposed to unfamiliar surroundings and unknown conditions. In case that the rescuers do not have sufficient experiences and knowledge regarding the search and rescue processes, the operations may be further delayed or even fail at the end. For example, there is a chance rescuers and volunteers get themselves injured in unexpected conditions.

To address the safety issues in search and rescue operations, the Civilian Report webpage could serve as a communication tool. Within the database schema (Figure III), there is an attribute to estimate the safety condition at the disaster site. This potentially opens the possibility of knowing preliminary safety condition of the area. In addition, information such as the Occupational Safety and Health Administration (OSHA) recommendations for search and rescue [25] and firstaid procedures and real-time recommendations posted by others is possible to be implemented into the Civilian Report service. Figure VI shows a framework for the process. Rescue workers who first arrive at the disaster site typically perform an initial hazard assessment and report the observed scene. Although they might not be responsible for mitigating hazards and saving lives in the uncertain environment, search teams can face situations that immediate actions are required (e.g., firstaid treatments, prevention of secondary incidents) before official rescue teams, task forces or emergency medical service teams arrive. In this case, knowledge and experience are crucial to provide the first-aid treatment and to protect search teams from potential hazards. The Civilian Report service can provide inexperienced volunteers and search workers with basic information during the search operations. As an example of the information to be provided, the OSHA furnishes information on potential hazards associated with the search and rescue activity and work practices for each task, including but not limited to: structural instability, heavy equipment operation, work near water, and confined spaces. In this respect, the Civilian Report webpage could help the first responders to take immediate actions at due time and can also contribute to estimating the number and type of equipment based on the initial hazard assessment uploaded by the first responders. Furthermore, the Civilian Report service could be used as a more active communication tool. For example, in addition to sharing site information (i.e., site photos and spatial data) with rescue experts outside of the disaster region, the first responders could benefit from recommendations suitable to the condition and situation by the remote experts, in terms of safety consideration in rescue operations. Therefore, the web service would have advantages to guide rescuers in urgent and dangerous circumstances.

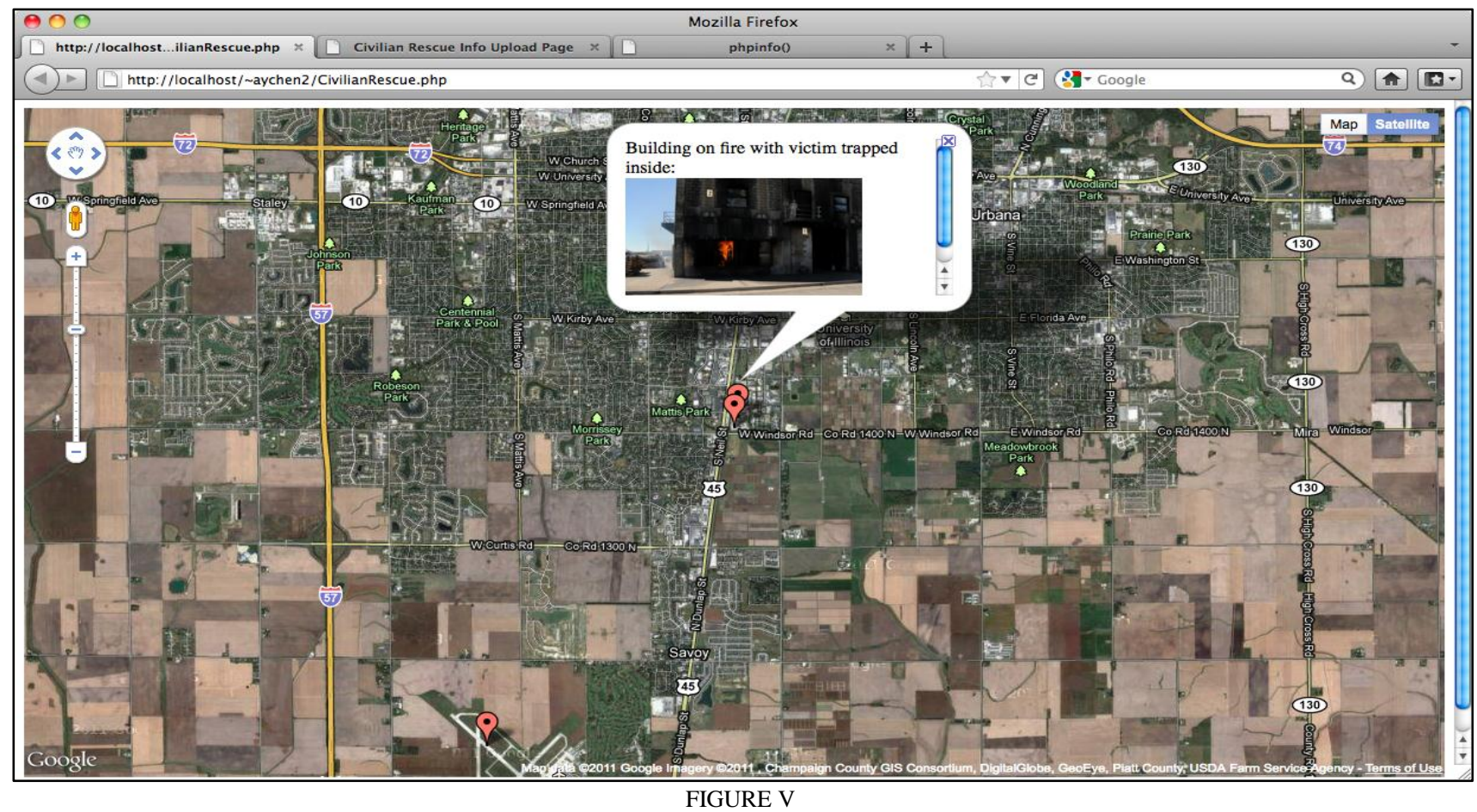

MAP INTERFACE OF THE SERVER SHOWING THE SUBMITTED INFORMATION FROM FigURE VI 


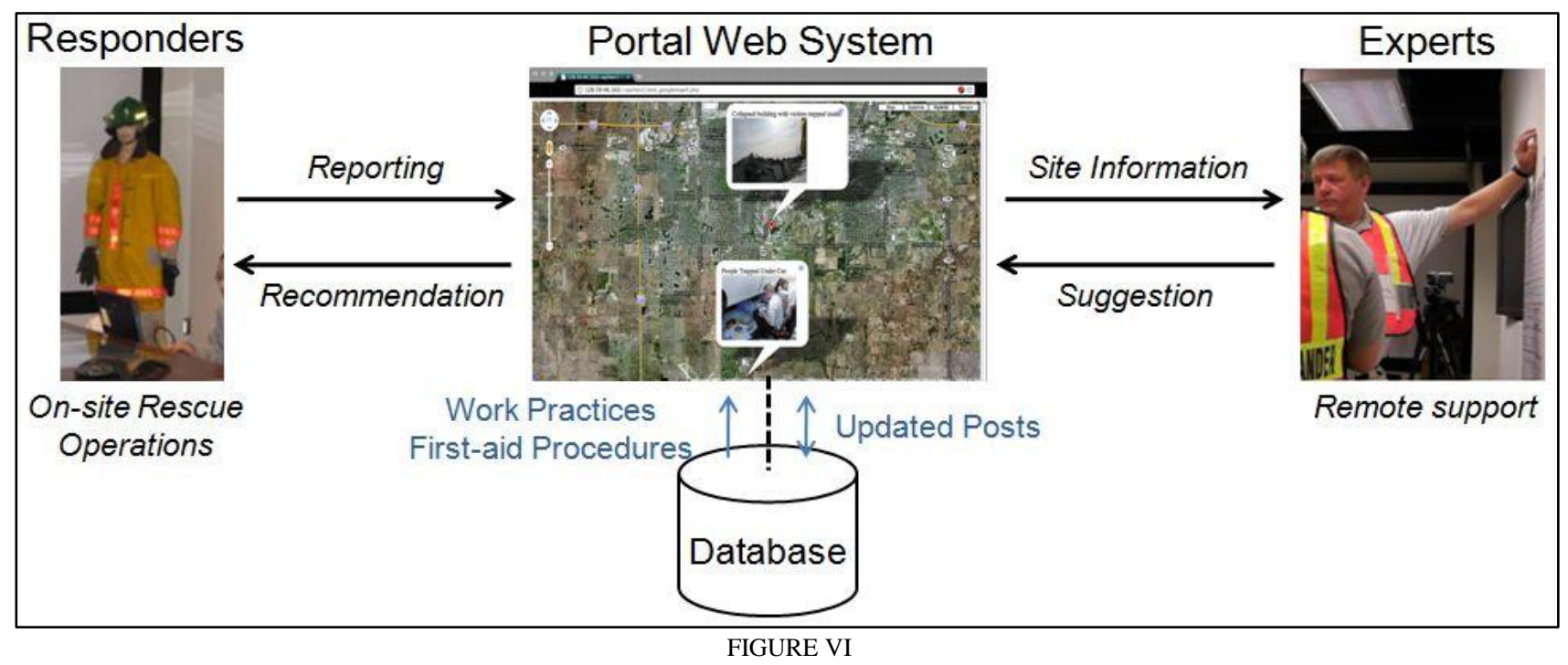

FRAMEWORK FOR SAFETY INFORMATION SHARING

\section{DISCUSSION}

The Civilian Report service could potentially guide the initial search and rescue operations for civilian rescue. The service could also be applied to response operations such as functionality restoration of critical infrastructure systems, - the transportation infrastructure, communication infrastructure and the power supply - to facilitate disaster response and recovery. The Civilian Report service could enable a Shared Vision to all stakeholders regarding information sharing for the emergency response goals, critical tasks, and needs of critical resources.

The Civilian Report service could be beneficial to the disaster response operations. For example, in the recent Earthquake that struck Christchurch, New Zealand [26], victims trapped under rubble sent text messages to people they know for help [27]. If the Civilian Report service was available at that time to the victims, they could have posted information of themselves with geospatial attributes available through the cell phone. Sharing of the spatial location of the victim could have facilitated the search and rescue operations.

Currently, the implementation of the Civilian Report service does not consider database security issues. As a result, future plans are to strengthen the security aspect of web development. In addition, the initial assessment and reporting from civilians need to have a standardized rubric established. The condition of victims as well as the safety of the disaster site needs more study and documentation to guide civilians report information.

In terms of safety considerations, future work will include the study on what information could be visualized and distributed through the webpage and what technological approaches would be useful to analyze the site for safety in rescue operations. To utilize the web service as a communication tool during rescue operations, visualization of information can play an important role. Visualization is a powerful tool for cognition [28] and perception of spatial information [29] as well as for problem solving and education [30]. With visualized information, search and rescue teams, volunteers, and remote experts could learn the site conditions and spatial configuration and would be able to suggest appropriate recommendations. The responders can also perceive information easily to take immediate actions properly without unnecessary delays. In this aspect, improving the capacity of the Civilian Report server is also critical to upload and store the visualized information, the file size of which is large in general. Furthermore, information technology approaches may have potential to be used for automated analysis and data collection of a disaster site. For example, the OSHA recommends making a site plan including detailed traffic flow to protect workers from mobile equipment. To collect data for the traffic control, computer vision techniques could be applied. Once video cameras are installed on a disaster site, the route and trajectories of equipment can be automatically captured using visionbased object detection and location tracking techniques [31,32], and the frequently overlapped areas could be identified and visualized on site images. By sharing this information through the Civilian Report service, rescue workers can avoid struck-by accidents, and official command and control teams can promptly and more efficiently plan for safety procedures (e.g., flaggers, traffic cones and devices) to accurately reflect the site conditions. The Civilian Report service could be developed in terms of functionality and capacity to perform a role as the hub for analyzing and communicating various types of safety procedures.

\section{CONCLUSION}

In this paper, a web service - Civilian Report - that takes information from civilians who discover information such as victim locations, damage conditions and resource demands, on the disaster affected area, is presented. The information is published on the digital 
map of the Civilian Report service for sharing. The context and assumptions of when the server would be used, along with the process of how a user would use the server, the architecture of the server, and a sample result are presented.

Although this ad hoc approach of information sharing could result in non-optimal distribution of equipment utilization, it is under the condition that the official command and control system is saturated. As a result, this web service could potentially be useful to guide disaster response through a distributed decision making approach.

Future work in addition to the discussed aspects, would be to further implement algorithms to make this process more efficient. In a large scale setting when the official command and control system is overloaded, demand for equipment could be in a great number. As a result, clustering of discovered demands needs to be performed on the server side, to avoid overwhelming information on the map interface. In addition, an algorithm to rank demand locations for a crew, based on the number of demand, spatial attributes, severity of demand and the capacity of the piece of equipment, could be highly useful to help decision making of the crew with automation when using the web service. Further more, information reporting must be effectively filtered and validated to avoid potential duplication of civilian report.

\section{ACKNOWLEDGEMENT}

This paper is an extension of the conference paper included in the proceedings of the 4th International Conference on Construction Engineering and Project Management [33]. The authors would like to thank the National Science Foundation for their support of the grant of award number 0427089, Bill Keller (Champaign County EMA), Mark Toalson (Champaign County GIS Consortium), and Richard Jaehne (Director of IFSI) and Gavin Horn (Research Program Director of IFSI) for their kind feedbacks. The authors also thank the anonymous reviewers of ICCEPM and JCEPM for their invaluable comments.

\section{REFERENCES}

[1] J. Sullum, R. Bailey, J. Taylor, J. Walker, K. Howley, D.B. Kopel, "After the Storm Hurricane Katrina and the failure of public policy", 2005

URL: $\quad$ http://www.reason.com/news/show/36334.html, [2/10/2009]

[2] D.M. McGuigan, "Urban Search and Rescue and the Role of the Engineer", M.S. thesis, University of Canterbury, New Zealand, 2002.

[3] J. Holguin-Veras, N. Perez, S. Ukkusuri, T. Wachtendorf, B. Brown, "Emergency Logistics Issues Affecting the Response to Katrina: A Synthesis and Preliminary Suggestions for Improvement", Transportation Research Record, no. 2022, pp. 76-82, 2007.

[4] "National Commission on Terrorist Attacks Upon the United States-9/11 Commission Report", Final Report of the National Commission on Terrorist Attacks Upon the United States, Official Government Edition, 2004.
[5] Select Bipartisan Committee (SBC), "A Failure of Initiatives, Final Report of the Select Bipartisan Committee to Investigate the Preparation for and Response to Hurricane Katrina", US Government Printing Office, Washington DC, 2006.

[6] C.E. Fritz, J.H. Mathewson, "Convergence behavior in disasters; a problem in social control", Washington, National Academy of Sciences-National Research Council, 1957

[7] T.E. Drabek, D.A. McEntire, "Emergent phenomena and the sociology of disaster: lessons, trends and opportunities from the research literature", Disaster Prevention and Management, vol. 12, no. 2, pp. 97-112, 2003.

[8] D. Wenger, "The Study of Volunteer and Emergent Organizational Response: Approaches and Issues for Future Research", College Station, TX: HRRC, Texas A\&M University, 1989.

[9] E. Auf der Heide, "Disaster Response: Principles of Preparation and Coordination", Online Book for Disaster Response, Center of Excellence in Disaster Management and Humanitarian Assistance, 1989,

URL: http://orgmail2.coe-dmha.org/dr/flash.htm

[10] J.M. Kendra, T. Wachtendorf, "Rebel Food... Renegade Supplies Convergence after the World Trade Center Attack", paper no. 316, Disaster Research Center, University of Delaware, Newark, 2001.

[11] K.J. Tierney, M.K. Lindell, R.W. Perry, "Facing the Unexpected: Disaster Preparedness and Response in the United States", Washington, DC: Joseph Henry Press, National Academy Press, 2001.

[12] E.L. Quarantelli, "Emergent Behaviors and Groups in the Crisis Time of Disasters", Disaster Research Center, University of Delaware, 1995.

[13] D. Wenger, "Emergent and Volunteer behavior during disaster: Research findings and planning implications", HRRC Publication 27P, Hazard Reduction Recovery Center, Texas A\&M University, College Station, TX, 1992.

[14] R.R. Dynes, "Community emergency planning: false assumptions and inappropriate analogies", International Journal of Mass Emergencies and Disasters, vol. 12, no. 2, pp. 141-158, 1994.

[15] D.S. Mileti, "Catastrophe planning and the grass roots: a lesson to the USA, from the USSR", International Journal of Mass Emergencies and Disasters, vol. 7, no. 1, pp. 57-67, 1989.

[16] R. Stallings, E. Quarantelli, "Emergent citizen groups and emergency management", Public Administration Review, vol. 45, pp. 93-100, 1985.

[17] OpenStreetMap., "Map volunteers help Haiti Search \& Rescue 24th January 2010", 2010,

URL: $\quad$ http://www.geog.ucsb.edu/events/departmentnews/680/how-map-volunteers-helped-haiti-search-amp-rescue/, [2010/9/24].

[18] E.L. Quarantelli, "Delivery of emergency medical care in disasters: assumptions and realities", Irvington Publishers, New York, 1983.

[19] Ushahidi, "Haiti: Taking Stock of How We Are Doing", 2010, URL: http://blog.ushahidi.com/index.php/2010/02/06/ushahidihow-we-are-doing/, [2010/9/24].

[20] A.Y. Chen, F. Peña-Mora, "A Decentralized Approach Considering Spatial Attributes for Equipment Utilization in Civil Engineering Disaster Response", (Accepted for Publication in) Journal of Computing in Civil Engineering, ASCE, [doi: 10.1061/(ASCE)CP.1943-5487.0000100], 2011.

[21] J.C. Biesmeijer, T.D. Seeley, "The use of waggle dance information by honey bees throughout their foraging careers", Behavioral Ecology and Sociobiology, vol. 59, no. 1, pp. 133142, 2005.

[22] F. Peña-Mora, A.Y. Chen, Z. Aziz, L. Soibelman, L.Y. Liu, K. El-Rayes, C.A. Arboleda, T.S. Lantz, A.P. Plans, S. Lakhera, S. Mathur, "A Mobile Ad-Hoc Network Enabled Collaborative Framework Supporting Civil Engineering Emergency Response Operations", Journal of Computing in Civil Engineering, ASCE, vol. 24, no. 3, pp. 302-312, 2010.

[23] Google Maps JavaScript API V3 URL: 
http://code.google.com/apis/maps/documentation/javascript/

[24] PHP Google Map API

URL: http://code.google.com/p/php-google-map-api/

[25] Occupational Safety and Health Administration (OSHA),

"OSHA Fact Sheet, Search and Rescue Operations", 2011,

URL:

http://www.osha.gov/OshDoc/data Hurricane Facts/search and rescue.pdf, [April 2011]

[26] BBC News, "New Zealand Earthquake: Rescuers Work Through Night", 2011,

URL: http://www.bbc.co.uk/news/world-asia-pacific-12540345

[27] Daily Mail News, “'I'm not going to give up': Mother's last message to rescuers from beneath Christchurch earthquake rubble before her mobile phone battery runs out", 2011,

URL: http://www.dailymail.co.uk/news/article-1359354/NewZealand-earthquake-A-mothers-message-beneath-Christchurchrubble.html

[28] C. Ware, "Visual Queries: The Foundation of Visual Thinking", Lecture Notes in Computer Science, vol. 3426, pp. 27-35, 2005.
[29] T. Keller, S.-O. Tergan, "Visualizing knowledge and information: An introduction", Lecture Notes in Computer Science, vol. 3426 , pp. 1-23, 2005.

[30] L.P. Rieber, "A Historical Review of Visualization in Human Cognition", Educational Technology Research and Development vol. 43, no. 1 , pp. 45-56, 1995.

[31] Z. Zhu, I. Brilakis, "Concrete Column Recognition in Images and Videos", Journal of Computing in Civil Engineering, ASCE, vol. 24, no. 4, pp. 478-487, 2010.

[32] J. Teizer, P.A. Vela, "Personnel Tracking on Construction Sites using Video Cameras", Advanced Engineering Informatics, vol. 23, no. 4, pp. 452-462, 2009.

[33] A.Y. Chen, F. Peña-Mora, "The Potential Use of a Public Web Service to Guide Converging Construction Equipment in Urban Search and Rescue", The 4th International Conference on Construction Engineering and Project Management, Sydney, February 16-18, 2011 